\title{
Uma chave para nossa desconcertante atualidade
}

\section{A key to our disconcerting world today}

\author{
FÁBIO FERREIRA DE ALMEIDA
}

É preciso reconhecer: a eleição de Jair Bolsonaro é um fenômeno político dos mais significativos e, a depender de como e de quando seu governo acabe, será um dos mais importantes da história política brasileira neste século. Esta afirmação, dita assim, peremptoriamente e logo de saída, a um só tempo constrange e surpreende.

Penso que a campanha que inundou as redes sociais declarando "não me representa" reflete esse constrangimento, mas também revela o lado mais perverso da nossa sociedade que contribuiu para ascensão desses vendilhões que aí estão: a saída fácil de eximir-se de toda responsabilidade; lavar as mãos, como se diz na língua do povo. Valeria a pena perguntar àqueles que bradam "não me representa": então quem representa? Desse reflexo defensivo foi vítima, do alto de seus noventa anos de idade, o eminente sociólogo Fernando Henrique Cardoso que, numa entrevista recente, referindo-se à crise que, anunciada, chegou, disse: “...nós elegemos Bolsonaro. Enfim, nós não, porque eu não votei nele...”. ${ }^{3}$ FHC é desses que, para se proteger sabe-se lá do que, está disposto a colar na janela de seu quarto e no vidro do seu carro o adesivo verde-amarelo com a hashtag "não me representa". O que significa tal reflexo se não uma recusa da política em seu sentido mais elementar? Afinal, se o eleito não me representa só porque eu não votei nele, isso significa necessariamente que só reconheço que me representa aquele em quem eu votei; se não for este, não estou implicado, não preciso me sentir concernido; não é culpa minha e... dane-se; dane-se o eleito, danem-se todos aqueles que votaram nele, dane-se o sistema que tornou possível a escolha. Esse reflexo defensivo, a meu ver, revela muito claramente aquele constrangimento, ao qual se mistura ainda uma boa dose de ressentimento e ainda uma outra paixão triste, que sempre acompanha esse tipo de atitude: a covardia.

\footnotetext{
${ }^{1} \mathrm{O}$ artigo foi publicado na Revista Ermira (http://ermiracultura.com.br/2020/05/27/uma-possivelchave-para-a-nossa-desconcertante-atualidade/) a quem agradecemos pela autorização de nova publicação na DIAPHONÍA.

${ }_{2}^{2}$ Professor Doutor junto aos cursos de Graduação e Pós-Graduação em Filosofia da UFG. E-mail: fbioferreira@yahoo.com.br.

3 https://www.youtube.com/watch?v=Dl8Xeginxms\&t=8s 58' 52". Nessa entrevista, FHC ainda critica fortemente os partidos e as forças políticas consideradas por ele como "anacrônicas" sem perceber o quanto ele próprio se tornou anacrônico. Enviar e-mails, comunicar-se via Skype ou ter um programa de TV (cuja contribuição efetiva para o que quer que seja é altamente discutível) não faz de ninguém vanguarda de nada.
} 
Mas podemos deixar de lado esse importante aspecto de nosso contexto atual, pois ele nos levaria a considerações muito mais exigentes do que esse artigo comportaria. Detenhamo-nos, antes, sobre o sentimento de surpresa que nos afeta de igual modo.

Essa surpresa se torna manifesta em toda sua verdade por meio da pergunta que acabou por inundar todos os círculos de discussão, ecoando até nos da direita quase reacionária, quase extrema, arrependida ou não: como é possível? Não vale a pena recordar aqui atitudes, seja do chefe do poder executivo seja dos ministros de estado nomeados por ele, que causam tal reação. Surrealista é um adjetivo que se tornou de emprego comum diante de tais situações, mas é um equívoco, pois é um uso que não faz jus a sua origem e menos ainda a sua originalidade, isto é, o movimento artístico que paga, por ter passado para a linguagem comum, um ônus parecido com o que a filosofia de Maquiavel paga pela popularização do adjetivo maquiavélico. Muito mais apropriado é o adjetivo "absurdo", ainda que, a cada semana ele venha se revelando insuficiente. De fato, se não tivéssemos que ver nos noticiários diários tais atitudes, tais declarações, elas bem poderiam ter sido criadas por algum Alfred Jarry ou Eugène Ionesco. Mas não há nada de artístico, nada de criativo no contexto com o qual nos confrontamos. Nossa realidade tornou-se sem afetos.

Outra pergunta que foi se tornando comum diante das ações desse governo e das atitudes de seus representantes, e que também traduz o espanto que elas causam é: que governo é esse? Pois é precisamente essa pergunta que gostaria de tomar a sério para tentar refletir sobre um dos elementos que, a meu ver, caracteriza esse governo e explica em grande medida não apenas sua ascensão como também suas atitudes. Esse elemento vem sendo apresentado com termo à la mode de Fake News, quando, e esta é a tese que gostaria de apresentar e defender aqui, na verdade não é.

No que segue, gostaria de explicitar por que julgo que não houve na campanha emprego disso que podemos chamar de Fake News e que nem o exercício do poder do qual essa campanha investiu esse governo se vale, rigorosamente falando, de "notícias falsas". Em seguida, gostaria de apresentar o que me parece ter ocorrido e por que é importante bem caracterizar essas estratégias, que denominaria de tecnologias contemporâneas de convencimento. Com isto, o que pretendo é formular uma tentativa de caracterização ${ }^{4}$ que a compreensão do fenômeno Bolsonaro exige e, deste modo, constituir uma chave de leitura que permita melhor enxergar aquilo do que nossa atualidade vem se constituindo.

\section{Não é Fake News}

\footnotetext{
${ }^{4} \mathrm{O}$ esforço de "caracterização" tem sido contraposto à atitude, equivocada e perigosa, de "caricaturização" das atitudes do governo pelo crítico e ensaísta João Cezar de Castro Rocha.
} 
Por certo, não se enganam aqueles que identificam nas chamadas Fake News uma das estratégias mais tradicionais e mais correntes, seja na política seja em qualquer situação de comunicação. A notícia falsa, quanto mais for apresentada com uma aparência que lhe confira alguma credibilidade, será tanto mais uma mentira. E a mentira, bem sabemos, é um dos atributos mais próprios da linguagem. Não é por outra razão que, ao longo de seus vinte e cinco séculos de história, a filosofia ocidental vem evoluindo em torno da linha constituída pelo entrelaçamento de, basicamente, dois fios: a linguagem e a verdade. Esses dois fios se entrelaçam de maneira curiosa: se verdade pode ser considerado um conceito totalitário, a linguagem, por sua vez, é o conceito que torna possível transgredir; é a linguagem que permite questionar, o que nada mais é que confronto com a verdade e recusa de seu caráter totalitário; a linguagem tanto permite contestar quanto permite confirmar a verdade, expediente que decorre necessariamente da dúvida, outro elemento eminentemente "linguageiro". Em suma, é a linguagem que torna possível aquilo que a verdade, sozinha, interdita: pensar. Grosso modo, podemos dizer que a noção de "regimes de verdade", que se tornou célebre na obra de Michel Foucault, se sustenta nesse fio cuja trama verdade e linguagem tecem. Os discursos também se amarram com esse fio.

É a isso que, em 1943, Alexandre Koyré dedica um ensaio tão belo quanto sucinto, e tão preciso e contundente quanto atual, intitulado Reflexões sobre a mentira. ${ }^{5} \mathrm{O}$ que Koyré quer ressaltar é o caráter distintivo, a originalidade, se poderia até dizer, da mentira moderna, pois, de acordo com o filósofo, nunca se mentiu tanto quanto em nossa época. E a característica que singulariza a mentira moderna, escreve Koyré, é que ela "é produzida em massa e se destina às massas" ${ }^{6}$ Essa formulação repercute e explicita as palavras iniciais do ensaio: "Nunca se mentiu tanto quanto em nossos dias. Nem nunca se mentiu de uma maneira tão deslavada, sistemática e constante”. ${ }^{7}$

Como se pode perceber, o que está em jogo é uma espécie de renovação da mentira que, seguindo certa inspiração heideggeriana que atravessa todo o texto de Koyré, reside no caráter técnico de sua moderna produção. A mentira, então, não pode mais ser entendida como falta ou desrespeito em relação ao princípio ético-discursivo da veracidade; tampouco ela poderá ser analisada como algum desvio da ambição metafísico-teórica à Verdade. Pelo modo como é produzida e pelos fins a que se destina, a mentira tornou-se, então, uma arma cuja crueldade específica reside em sua capacidade de criar um grupo de eleitos que acreditam conhecer a verdade dada - mas que, na verdade, é uma mentira - e, em nome

\footnotetext{
${ }^{5}$ KOYRÉ, A. Réflexions sur le mensonge. Paris: Allia, 2016. Há uma tradução brasileira desse texto realizada por Caio Souto e publicada na Revista Ipseitas (São Carlos, vol. 5, n. 1, p. 119-132, jan-jun, 2019)

${ }^{6}$ KOYRÉ, A. Réflexions sur le mensonge. Paris: Allia, 2016, p. 10.

${ }^{7}$ Idem, p. 7 .
} 
dela, subjugam e se autorizam aniquilar qualquer possibilidade de diálogo, de contestação, de dúvida e, enfim, de pensamento, sempre para o bem da verdade. É o rompimento daquela trama que se tece com o fio-verdade e o fio-linguagem; é o esgarçamento do pensamento como tal. Então a fala, reduzida a ordem, a ditame, se coloca a serviço da "verdade" ora proclamada.

É claro, o que está em jogo e o que impulsiona as reflexões de Koyré é o apogeu do totalitarismo na Europa. E quando Koyré afirma que nunca se mentiu tanto quanto em naquela época, ele não está apontando um salto quantitativo na história da mentira, que é tão longa quanto a da linguagem, mas uma transformação qualitativa: "A distinção entre a verdade e a mentira, entre o imaginário e o real, permanece válida no próprio interior das concepções e dos regimes totalitários. É tão somente o lugar e o papel deles que são, de certo modo, invertidos: os regimes totalitários estão fundados sobre a primazia da mentira" ${ }^{8}$ A essência ou, se quisermos, de maneira irônica, a "verdade" do totalitarismo é propriamente a mentira, e a primazia da mentira reflete exclusivamente a verdade do momento. O tema da verdade e o problema da linguagem se cruzam agora com uma outra questão: a questão do poder que, nos regimes totalitários, também se separa deles e, assim, se perde. Hannah Arendt, leitora de Koyré, também dedicou análises preciosas a esse respeito. O célebre ensaio sobre As origens do totalitarismo (1951) $)^{9}$ é exemplar nesse sentido, mas também mereceram grande atenção da filósofa outros conceitos que gravitam em torno da questão do poder: política, violência, autoridade, julgamento, além, é claro, da mentira.

A estratégia totalitária de produção e de propagação técnica da "verdade" tem em vista, portanto, a criação disso que, em relação às ordens religiosas e às sociedades secretas, eram os iniciados, e que agora são "as massas". O que distingue o sacerdote iniciado e seu séquito do líder totalitário e seus seguidores é que este não esconde nada; a massa o segue cegamente - estupidamente - porque, para ela, está claro que é ele quem diz a verdade, ele está com a verdade, ele a detém, é ele o verdadeiro. Surgem, com isso, os veneráveis atributos, louvados como qualidades, dos atuais líderes totalitários: autenticidade, espontaneidade e, quando eleito, legitimidade. É para caracterizar esse mecanismo que faz funcionar o fenômeno totalitário que Koyré cria a expressão "conspiração às claras"[conspiration en plein jour]:

Os regimes totalitários nada mais são que tais conspirações, que são fruto do ódio, do medo, da inveja, e alimentados por um desejo de vingança, de dominação, de rapina; conspirações que tiveram êxito, ou melhor - e este é um ponto importante - são

\footnotetext{
${ }^{8}$ Idem, p. 12-13.

9 ARENDT, H. As origens do totalitarismo. Trad. Bras. Roberto Raposo. São Paulo: Companhia das Letras, 2000.
} 
conspirações que tiveram um êxito parcial: elas conseguiram se impor em seu país, conquistaram o poder, tomaram o Estado. ${ }^{10}$

Ora, esse êxito continuará sendo parcial enquanto a conspiração estiver restrita a determinados territórios, enquanto o domínio que se quer totalitário permanecer circunscrito a determinada fronteira e, portanto, limitado por elas. Enquanto não for efetivamente total, ou seja, enquanto não cooptar a totalidade dos homens, todos os espíritos, a conspiração totalitária, em seu sucesso apenas parcial, rigorosamente fracassa. Às claras, em plena luz do dia é que a conspiração totalitária projeta sombras; a verdade explícita, despudorada, devassada - que reflete tão somente o primado da mentira - projeta para além daqueles limites a mentira como a "verdade" desse sistema. Foi com essa lucidez admirável que Alexandre Koyré enxergou esse mecanismo em ação na Europa dos anos 1940, e não deixa de ser tanto mais surpreendente, diante do cenário que cada vez mais se firma atualmente em países como o Brasil, uma passagem como esta:

É bem verdade que Hitler (assim como os outros chefes de países totalitários) anunciou publicamente todo seu programa de ação. Mas o fez justamente porque ele sabia que "os outros" não acreditariam, que suas declarações não seriam levadas a sério pelos não-iniciados; foi justamente dizendo a eles a verdade que ele podia estar certo de enganar e de anestesiar seus adversários. Essa é uma velha técnica maquiavélica de mentira em segundo grau, técnica perversa mais que qualquer outra, e na qual a verdade ela mesma se torna, pura e simplesmente, um instrumento de decepção. Parece bem claro que essa "verdade" nada tem em comum com a verdade."

Basta substituir Hitler por Bolsonaro (por Trump, Orbán, ou qualquer desses mentirosos a ascenderam mundo afora dentro de suas respectivas fronteiras) para que essas Reflexões sobre a mentira assumam o esmagador e áspero frescor da atualidade. $\mathrm{O}$ que ocorre em nossos dias será uma repetição ainda mais cruel daquele primado da mentira que caracteriza os regimes totalitários que emergiram após a Segunda Guerra Mundial? Sem pretender dar aqui uma resposta a uma questão tão complexa, parece que podemos, pelo menos, convir que o mecanismo persevera e que, com o rearranjo das potências mundiais após 1945 sob a batuta dos EUA (isso envolve, inclusive, o longo período de Guerra Fria), o capitalismo de mercado e o liberalismo econômico se firmaram como importantes aliados nessa mesma conspiração às claras. Como não reconhecer que o que o capitalismo moderno e o liberalismo econômico produzem é, antes de tudo, mentira? Como nos regimes totalitários, é precioso expor a verdade para, assim, con-

\footnotetext{
${ }^{10}$ KOYRÉ, A. Op. cit., p. 32-33.

${ }^{11}$ Idem, p. 29-30.
} 
vencer as massas de que estão certas. E o que são "as massas" senão a uniformização das subjetividades por meio da mentira?

Não é por outra razão que, no Brasil, por exemplo, mas certamente também em países bem mais desenvolvidos e bem mais "civilizados", qualquer campanha eleitoral não prescinde de um "marqueteiro"; o marketing político é a forma atualizada da propaganda, cujo objetivo, hoje em dia como outrora, é tão explícito quanto o nome que a designa: propagar uma verdade para que seja seguida, isto é, para que seja irrefletidamente aceita; para que não se pense e para que, assim, não importe mais a verdade. Os fenômenos da moda refletem isso bem, assim como a idolatria a personalidades, que converte pessoas em produto. Nesse sentido, podemos até nos perguntar como é possível que alguém seja tão idolatrado, exposto e, afinal, consumido com aquele mesmo espanto com que a pouco perguntávamos: como é possível esse governo?

Não é por acaso, aliás, que mundo afora são essas personalidades "de massa" que acabam assumindo, não cargos importantes, mas a presidência, isto é, o rosto (a representação) de países com poder de decidir a configuração do mundo. Também não parece ser por acaso que os EUA foram os pioneiros nessa moda, seguidos da Itália, para ficarmos apenas com dois exemplos de países ricos, industrializados, "desenvolvidos", "civilizados". Isso, de fato, não deixa de ser um feito espantoso.

Tais fenômenos, e com isto retomo a elaboração da hipótese geral, na medida em que são produtos daquele mecanismo fundado sobre o primado da mentira, confirmam a eficácia das Fake News, das notícias falsas ou, para repetir novamente, da propagação explícita e deslavada da mentira para arregimentar as massas. No entanto, o que temos visto nos últimos anos - talvez desde antes, mas certamente pelo menos desde a eleição de Donald Trump, nos EUA - é um fenômeno muito distinto. E o que o distingue é que ele simplesmente prescinde daquele que é o elemento fundamental da conspiração às claras, a saber: as massas. Isso, evidentemente, não quer dizer que não há mais Fake News, mas tão somente que, como estratégia política, as notícias falsas talvez estejam já ultrapassadas e, se tudo isso faz algum sentido, o que é certo é que os marqueteiros perderam suas funções. ${ }^{12} \mathrm{~A}$ mentira como que perdeu sua eficácia de arma de dominação política do eleitorado. Mas o pior é que, se de fato for assim, essa não é uma boa notícia.

O que torna o cenário contemporâneo particularmente perigoso é que as fronteiras que cercavam o séquito do líder totalitário de repente desapareceram. Como num passe de mágica, toda barreira foi superada, e, precisamente, pela expansão do liberalismo exclusivamente econômico; aliás, menos que exclusiva-

${ }^{12} \mathrm{O}$ recurso ao marketing não foi, por exemplo, um aspecto relevante na campanha que elegeu Jair Bolsonaro em 2018, o que pode ser uma acusação às campanhas anteriores. 
mente econômico, exclusivamente financeiro. Desde a última década do século XX essa "nova ordem mundial", vem sendo designada pelo termo "globalização". A queda do muro de Berlin, todos sabemos, foi um importante acontecimento apenas simbólico: ele simbolizou exatamente o desaparecimento da última fronteira que limitava o alcance do império da mentira, a última barreira que continha as massas. E se foi apenas simbólico, é porque o que já não podia mais suportar aquele símbolo tão cruel, tão pesado, tão duro e significativo, era esse elemento que já tinha ganhado a guerra: o capitalismo financeiro internacional. Neste cenário, muito mais radical e muito mais eficaz que aquela nova ordem mundial da qual tanto se falou a partir de 1989, erguem-se impérios privados e destroemse sociedades inteiras. De modo que, como tentei sugerir acima, se as Fake News ainda se fundam basicamente sobre a mentira, nesse novo contexto a mentira está a serviço do que no início propus designar como tecnologia contemporânea de convencimento.

\section{Tecnologias contemporâneas de convencimento}

Os objetos culturais (e a este respeito continuam pertinentes as teses sobre a indústria cultural dos pensadores frankfurtianos), assim como os noticiários e os grandes meios de comunicação, continuam sob o domínio da mentira, aquela mesma que Koyré e Arendt tão bem perceberam. Uma nova tecnologia surge então, muito mais que para se aliar, para sugar o que a produção em massa da mentira produz, isto é, basicamente: desejo, necessidade, vontade. Essa nova tecnologia é a dos mega data que, em última instância, constituem a mercadoria que empresas especializadas se dedicam a explorar economicamente. A exploração econômica desses enormes "bancos de dados" é que é feita tecnologicamente para convencer, seja política seja comercialmente..$^{13}$

O termo tecnologia aqui deve ser entendido nessa acepção de uma ferramenta eletrônica, devidamente patenteada que, como as técnicas e os instrumentos, são criadas para resolver problemas comuns da vida dos homens. Esses problemas, no entanto, se atualizam. Não se trata mais de transportar uma carcaça de animal ou de abater uma árvore e transportar seu tronco; não se trata mais de atravessar um rio. Na verdade, os obstáculos para os quais as tecnologias contemporâneas propõem soluções espetaculares são obstáculos à eficácia, à rapidez de produção; são obstáculos não para a vida dos homens, mas para o crescimento capital; em última instância, se levarmos a argumentação até o seu limite, as tecnologias criam soluções para problemas, na verdade, inexistentes. Não tenho aqui a pretensão de analisar o processo de constituição dessa novidade, nem seus impactos econômicos e sociais, o que certamente já vem sendo feito por pessoas

${ }^{13}$ A invasão de computadores e celulares com publicidade de produtos visualizados numa pesquisa pela Internet ou numa trivial navegação pela rede, ou mesmo relacionada a algum interesse mencionado numa conversa, já se tornou, para nós, algo banal. 
bem mais competentes. No entanto, podemos perguntar: qual o problema efetivo para a vida dos homens as modernas tecnologias de comunicação resolvem? Apenas para termos um exemplo: um telefone celular hiperconectado ou um relógio de pulso através do qual se tem acesso a plataformas como Facebook ou Whatsapp, resolve que tipo de problema? Aquela pergunta e estes exemplos, claro, não foram escolhidos ao acaso: são essas tecnologias de comunicação e de informação - e aqui vale perceber que retomamos, num outro registro, o tema da mentira que estão na base dos mega bancos de dados a partir dos quais se tem orientado, com uma estratégia surpreendentemente astuta, os destinos do mundo. Essa aparelhagem tecnológica e seu modo de funcionamento nos permite compreender um pouco melhor fenômenos como a eleição de dirigentes mundiais como Trump, Bolsonaro e outros. Mas, de que modo?

Essa pergunta faz ressaltar o termo convencimento. Diferentemente do marketing e da propaganda fundados sobre a mentira e destinado a criação e domínio das massas, o convencimento é individualizado. Essa diferença também pode ser dita, de modo mais conceitual. Por um lado, a propaganda (política ou qualquer outra) molda eficazmente as subjetividades àquele produto (ou candidato) que ela precisa vender (ou eleger); a mentira é elaborada de modo a criar um efeito de rebanho que conduz o maior número possível de indivíduos na mesma direção; mobilizam-se medos comuns, anseios comuns, problemas comuns e se propõe uma única solução - mentirosa, por certo - que, mobilizados todos, torna-se uma verdade de momento. Os slogans da propaganda nazista ilustram muito bem essa criação de massas. Já a compreensão do convencimento que gostaria de propor é muito distinta. $\mathrm{O}$ convencimento, primeiramente, não se destina às massas, mas ao indivíduo. $\mathrm{O}$ convencimento não cria uma verdade de momento, mas revela para um sujeito individual, singular, que o que ele pensa é que é verdade. Em seguida, apresenta a essa multidão de donos da verdade uma realidade que, parafraseando a fórmula medieval, se adequa a cada intelecto individual, atomizado; uma prova, enfim, para cada pensamento ou para cada conhecimento. Deste modo, se a propaganda - que é, em sua essência, Fake News molda as subjetividades à coisa ou à realidade que ela mentirosamente propõe, por meio das tecnologias contemporâneas de convencimento é a realidade mesma que se molda a cada subjetividade singular.

Isso talvez aponte um caminho para compreendermos porque pessoas inteligentes, até cultas, pessoas com as quais convivemos e das quais gostamos, acabam aderindo a certos discursos aberrantes. Por mais cultas e inteligentes, elas foram convencidas a partir daquilo no que mais intimamente creem, com base em suas convicções mais profundas, dimensão à qual, eis a novidade, se tem acesso contemporaneamente por meio das empresas que comercializam mundo afora os mega data. Ainda nos anos 1970, o sociólogo americano Richard Sennet dissecou 
a transformação profunda que tornou possível essa eficácia das tecnologias contemporâneas de convencimento no livro The fall of public man (1977), cuja tradução brasileira incluiu o subtítulo: "as tiranias da intimidade". ${ }^{14}$ Neste livro, Sennett apresenta uma história da alienação contemporânea, que é muito diferente daquela a partir da qual Marx pensou o capitalismo no século XIX. Vivemos agora sob o império da personalidade, do eu, do indivíduo. "Multidões de pessoas", escreve Sennet, "estão agora preocupadas, mais do que nunca, apenas com as histórias de suas próprias vidas e com suas emoções particulares; essa preocupação tem demonstrado ser mais uma armadilha do que uma libertação". ${ }^{15} \mathrm{E}$ conclui:

A sociedade em que vivemos hoje está sobrecarregada de consequências dessa história: o evanescimento da res publica pela crença de que as significações sociais são geradas pelos sentimentos de seres humanos individuais. Essa transformação camuflou duas áreas da vida social. Uma é o âmbito do poder, a outra é o âmbito das aglomerações em que vivemos. ${ }^{16}$

Nessa segunda era da mentira em que vivemos, parece muito claro que essa armadilha é, para aquele que cai nela, uma libertação; ela é, como se diz comumente, a mais pura verdade. Nesta chave de leitura, também é possível analisar a repetição ad nauseam por Bolsonaro, por exemplo, dessa passagem do Evangelho de João: "conhecerdes a verdade e ela vos libertará". Evidentemente não vale a pena nos ocuparmos aqui em demonstrar a utilização chula da passagem provavelmente pinçada por algum pastor aliado e soprada em seu ouvido. Mas ela, de fato, alimenta o ambiente que torna possível tais acontecimentos; ela calha perfeitamente com o diagnóstico proposto por Sennett. É a intimidade de cada um que dita a verdade que fundamenta menos o social que aglomerações. $\mathrm{O}$ que as tecnologias contemporâneas de convencimento fazem, em suma, é convencer cada um, apoiando-se em suas intimidades mais secretas, de que sua verdade é a boa, que é ele (o indivíduo) quem está com a verdade. O líder é apenas um ícone que se encarrega de levar adiante, ou a cabo, essa mentira. As tecnologias atuais de comunicação, assim, combinam perfeitamente com esse cenário. A segunda década deste século começa como prova da eficácia dessas novas estratégias e termina confirmando ainda mais o fenômeno.

\section{Os levantes e a resposta reacionária}

O ano de 2010 terminou pressagiando mais justiça e sob os auspícios de corajosas reivindicações por maior participação e por mais democracia mundo afora. Mas as revoltas vieram calibradas com seu revés.

\footnotetext{
${ }^{14}$ SENNETT, R. O declínio do homem público. As tiranias da intimidade. Trad. Bras. Lygia Araújo Watanabe. São Paulo: Companhia das Letras, 2001.

${ }^{15}$ Ver p. 17.

${ }^{16}$ Idem, p. 411.
} 
Os levantes da chamada Primavera Árabe só foram possíveis devido aos novos meios de comunicação, que também se revelaram meios de mobilização. Foi por meio de telefones celulares e computadores que os jovens, desde o oriente médio até os Coletes Amarelos, marcaram suas manifestações de protesto. Diante dos resultados efetivos deste e de outros eventos seria possível até suspeitar (num exercício de imaginação conspiratória) que forças que tinham compreendido muito bem o significado e o alcance do "declínio do homem público", a aniquilação da ação (outra temática central na filosofia de Hannah Arendt), o esvaziamento da política, bem como o papel da mentira nesse processo, calmamente observavam, com seus monóculos, suas cartolas e seu charutos, a juventude se revoltar como quisesse pois, assim, entregariam de mão beijada uma receita perigosa que ela, do alto de sua ingenuidade mais autêntica e mais profunda, não sabia que tinha. Essas novas forças, hábeis em aprender lições, não só não desperdiçaram esta última como passaram a dominá-la melhor do que ninguém, combinando-a de maneira formidável com a "tirania da intimidade". E, novamente, só puderam fazê-lo porque eles é que possuem, não apenas os meios de produção, mas sobretudo os meios de comunicação, o que agora é o mais importante.

Essa correlação entre os levantes que marcaram o início dessa década que termina tristemente e a ascensão avassaladora de governos, quando não de extrema-direita, radicalmente conservadores e ultraliberais, naturalmente foi logo percebida por observadores e analistas de todo tipo. No Brasil, essa reação ao fenômeno foi particularmente rápida. Logo arrefeceram os ânimos daqueles que invadiram as ruas país afora empunhando as mais diversas pautas, inclusive com cartazes dizendo que partidos e políticos não os representava. Cerca de seis meses depois, com a instauração da chamada Operação Lava-Jato e a espetacularização orquestrada do combate à corrupção, pipocaram movimentos que coordenaram uma nova invasão das ruas, só que agora a energia como que refluía e, ao invés de empurrar as coisas para frente (ainda que fosse para destruir o que estivesse no caminho) arrastava tudo para abismos muito profundos; tal retrocesso nos puxava para uma obscuridade ácida e pegajosa. Esse revés se fez sentir de diferentes maneiras no Oriente Médio, no Reino Unido, nos EUA, na Grécia, na Hungria, etc. No Brasil, as cores da bandeira e o hino nacional acabaram tomando os espíritos daqueles que, pelos celulares, pelos computadores, pelas mais diversas plataformas de comunicação e redes sociais, haviam, meses antes, atendido a um chamado muito diferente. Com a Polícia Federal nas ruas a cada manhã fazendo justiça e colocando no camburão políticos, marqueteiros de campanhas eleitorais e empresários, o povo refluiu às ruas paramentado, não mais para reivindicar, mas para comemorar e estimular uma falsa descoberta: a de que políticos cometem atos de corrupção, a de que marqueteiros de campanha mentem e a de que 
empresários tem seus esquemas para ganhar licitações. ${ }^{17}$ Claro, pode-se dizer que, de fato, tais atitudes eram conhecidas e que o que se comemorava era a prisão, a responsabilização, a punição daqueles que, como até então se acreditava, jamais pisariam sequer numa sala de polícia, que dirá numa cela. Pois foi precisamente isso que o Brasil comemorou vestido de verde-amarelo a partir de 2014: o que todos sabiam e o que todos, segundo registros diversos, queriam, tornava-se finalmente "verdade".

A reeleição de Dilma Rousseff neste mesmo ano era algo com que os arranjadores da farsa talvez não contassem, mas isso foi só um buraco na pista reta, lisa e convenientemente iluminada que nos conduziria até 2018. Um golpe malajambrado bastaria contornar esse obstáculo que, ademais, nem era difícil perceber no meio do caminho. O mais importante era que já estava em ação a estratégia. E aquela estrada, logo em seguida, se esfacelaria como biscoito seco.

Se prefiro o termo "estratégia" para me referir a essa "estrada", é para preservar a dignidade da noção de "método", que remete à mesma imagem. O termo (não tanto a ideia) tem sido muito frequentemente empregado para se referir às atitudes de Bolsonaro. Nesse uso do termo, os príncipes de agora, os economistas, estão representados por Monica Bolle que, em 2019, escreveu para a Revista Época a coluna intitulada "A Loucura como método", na qual, grosso modo e como de hábito, faz o elogio nostálgico da loucura metódica da política econômica da turma do Plano Real contra a chamada nova matriz econômica de Guido Mântega, que ela identifica como "loucura sem método", tudo isso como se a história não existisse. ${ }^{18}$ No mesmo ano, o professor de filosofia da Unicamp e diretor do Cebrap, Marcos Nobre, publicou na Revista Piauí o artigo intitulado "Caos com método", no qual insiste na tese de que tudo o que Bolsonaro faz é bem refletido e visa unicamente cristalizar o exíguo apoio de seus seguidores mais néscios, dispostos a segui-lo, mesmo que seja para o fim do mundo. Para tanto, segundo Nobre, o presidente estaria conscientemente apostando no caos generalizado a fim de provar para os seus que ele - detentor da "verdade" - é que os libertará. ${ }^{19} \mathrm{Ou}$ tros artigos e colunas recorrem à ideia de método, nessa tentativa um pouco de-

\footnotetext{
${ }^{17}$ Como a má-fé grassa e há sempre desonestos de todo tipo, faz-se necessária essa breve nota para ressaltar que não se trata aqui de justificar tais atos, no mais, altamente reprováveis e para os quais todos esperam punição. Interessa aqui analisar a utilização astuta, porque mentirosa, dos valores que todos compartilham.

18 Ver http://www.fundacaoastrojildo.com.br/2015/2019/o5/30/monica-de-bole-loucura-comometodo/

19 Ver Revista Piauí, no 151, abril de 2019, pp. 30-3. Disponível em https://piaui.folha.uol.com.br/materia/o-caos-como-metodo/
} 
sesperada que nos aflige a todos de entender "que governo é esse”, "como é possível". ${ }^{20}$

A palavra método apenas revela a tentativa de enxergar alguma racionalidade ou inteligência nas atitudes desse e de outros governos. Marcos Nobre reitera sua tese numa entrevista recente para o jornal El País quando, ao ser perguntado se Bolsonaro mostrou-se incapaz de lidar com a atual crise sanitária que assola o mundo, começa sua resposta dizendo: "Me irrita um pouco quando a pessoa afirma que ele é burro ou louco...”. ${ }^{21}$ Acho que Nobre, assim como outros intelectuais públicos relevantes, se equivoca quanto a este que não é um simples detalhe: não foi nem Bolsonaro, nem a equipe que elaborou sua "campanha", quem concebeu o ardiloso sistema que o elegeu e que o tem mantido no cargo até agora. Prova suficiente disso são os semanais, para não dizer cotidianos, atropelos que o governo como um todo, e o presidente em especial, vêm cometendo, comprometendo todas as áreas e todos os índices, comprometendo até mesmo a mínima institucionalidade de que ele necessita para manter-se no cargo. Por isso, Bolsonaro, como Berlusconi, Trump, Boris Johnson e outros são tão somente aqueles que se dispuseram a ceder seus rostos e vozes àquela estrutura tão difusa quanto eficaz que superou a mentira e, com ela, a dependência das massas.

Diria, portanto, que a estratégia se vale das mais modernas tecnologias de informação para atingir o ponto que, no íntimo de cada um, ao mesmo tempo mais machuca e o que mais conforta. Com isto, torna-se possível construir para cada um aquele que alivia o mal e estimula o contentamento. Ele não se identifica com ninguém, por isso pode ser o governante. Ao mesmo tempo, todos se veem representados por ele, todos podem dizer dele: "me representa". Esse monstro desfigurado talvez possa ser nomeado com a expressão que, pejorativamente, se emprega para designar "o povo", o "cidadão comum", a saber: ele é um zé ninguém. O que a utilização astuta e perversa dos mega bancos de dados permitiu foi dar concretude (rosto e voz) a essa figura demoníaca que, se por um lado é ninguém, por outro, como um Zé, ou seja, é todo mundo. Impossível não lembrar aqui do magnífico romance de José Saramago, Todos os nomes.

É neste sentido que, com essas tecnologias contemporâneas de convencimento, não estamos mais lidando com "notícias" (News), cuja verdade ou veracidade sempre foi e sempre será problemática. Se assim fosse, já teríamos os meios para, se não dirimir completamente, pelo menos diminuir suficientemente os

\footnotetext{
${ }^{20}$ Poupo os eventuais leitores de me deter sobre os sofríveis três parágrafos que Bolívar Lamounier cometeu na Revista Isto $\hat{E}$, em pleno mês de maio 2020. No qual só mostra o quanto o vírus do rancor e do ressentimento é persistente (https://istoe.com.br/parece-loucura-mas-tem-metodo/). ${ }^{21} \mathrm{https} / / /$ brasil.elpais.com/brasil/2020-04-27/nobre-as-chances-de-bolsonaro-sao-baixas-quandoroberto-jefferson-entra-e-o-beijo-da-morte-de-qualquerpresidente.html?fbclid=IwAR2bdT2mY82J8CaZ33OPcL9VNISrdm5i4GtXxLzyAtmkczsZWnA7AqkSa3RI
} 
efeitos da mentira. Mas estamos lidando com algo muito mais radical. E o que é ainda pior: com algo absolutamente inédito. Se tudo isso fizer algum sentido, talvez seja possível ler os acontecimentos cada vez mais desconcertantes da nossa atualidade a partir dessa chave. Talvez com ela sejamos capazes de liberar alguma reação que ninguém pode dizer qual será, mas que, liberada, crie um novo revés que atinja essa estrutura cuja eficácia reside em seu caráter planetário (total) e íntimo. A aposta pode ser que, a aliança de extremos tão distantes imprima no núcleo dessa força avassaladora alguma fragilidade maior que a nossa.

Submissão: 18. 05. 2020 / Aceite: 20. 05. 2020 